\title{
Proximate Determinants of Under-Five Mortality in Ethiopia: Using 2016 Nationwide Survey Data
}

This article was published in the following Dove Press journal:

Pediatric Health, Medicine and Therapeutics

\author{
Chaltu Fikru' \\ Masrie Getnet ${ }^{2}$ \\ Tamrat Shaweno (D) \\ 'Department of Epidemiology, Faculty of \\ Public Health, Jimma University Institute \\ of Health, Jimma, Ethiopia; ${ }^{2}$ Biostatistics \\ Unit, Department of Epidemiology, \\ Faculty of Public Health, Jimma University \\ Institute of Health, Jimma, Ethiopia
}

\begin{abstract}
Introduction: Although there has been a remarkable decline in under-five mortality through the decades, it is still highest in socio-economically disadvantaged countries, including Ethiopia. The benefits of reducing under-five mortality have been highly emphasized in the ambitious target of Sustainable Development Goals. The risk factors of under-five mortality have not been exhaustively researched in Ethiopia using recent nationwide survey data.

Objective: This study aimed to determine the risk factors of under-five mortality using the recent nationwide survey data.

Method: The data source for this study was the 2016 Ethiopian Demographic and Health Survey. Bivariate and multivariable logistic regression analysis was conducted and statistical significance was declared at $\mathrm{p}$ value $<0.05$.

Results: The data for a total of 10,641 under-five children were analyzed and the under-five mortality rate was 67 per 1000 live births in this study. In the final model, rural residence (AOR=2.0, [1.20, 3.30], $P=0.008$ ), mothers who gave birth with preceding birth intervals of shorter than 24 months $(\mathrm{AOR}=2.12, \mathrm{CI}=[1.72,2.61], P<0.000)$, multiple births $(\mathrm{AOR}=4.74$, $\mathrm{CI}=[3.34,6.69], P<0.000)$, very small size of child at birth $(\mathrm{AOR}=1.43, \mathrm{CI}=[1.10,1.85]$, $P=0.007)$, and being male $(\mathrm{AOR}=1.30, \mathrm{CI}=[1.07,1.57], P<0.008)$ showed significant association with under-five mortality compared to their counterparts.

Conclusion: Under-five mortality was significantly associated with place of residence, preceding birth interval, plurality, size of child at birth, and sex of the child. Thus, special emphasis should be placed on children with rural residence, preceding birth interval of shorter than 24 months, very small size of the child at birth, and male children.
\end{abstract}

Keywords: under-five mortality, EDHS 2016, determinants, Ethiopia

\section{Introduction}

Despite the global progress in reducing child mortality over the past few decades, an estimated 5.4 million children under the age of five died in 2017 - roughly half of those deaths occurred in sub-Saharan Africa. ${ }^{1}$ In 2017 , the under-five mortality rate in low-income countries was 69 deaths per 1000 live births - around 14 times the average rate in high-income countries ( 5 deaths per 1000 live births). ${ }^{2}$

The sustainable development goal's target is to reduce under-five mortality rate to below 25 under-five deaths per 1000 live births at the end of $2030 .^{3}$ To reach this target, much effort would be needed in Africa. ${ }^{4,5}$ Even though there has been a global decline in the death rates of under-five children, the probability of a child dying before reaching their 5th birthday remains the highest in subSaharan Africa, including Ethiopia. ${ }^{6}$ Although various measures have been taken to decrease under-five mortalities, most of the sub-Saharan countries show very
Correspondence: Tamrat Shaweno Email babiynos@gmail.com 
high under-five mortality rates. ${ }^{5}$ Nonetheless, under-five mortality rate in Ethiopia is still highest. ${ }^{7}$

Different studies have been conducted to identify the factors influencing under-five mortality. Risk factors that predicted under-five mortality included maternal education, maternal age, wealth index, educational status, birth order, preceding birth interval, and birth weight. ${ }^{8-10}$ Furthermore, sex of the child, place of delivery and geographical region had an association with increased risk of under-five mortality. ${ }^{9-11}$ Following the publications of EDHS 2016 findings, Ethiopia developed a five-year strategy. The strategy identified and prioritized 39 high impact and cost effective newborn and child survival interventions with key guiding principles for implementation of the strategy including equity and accessibility; community engagement, empowerment and ownership; integration; partnership; efficient use of resources; innovation and use of technology; evidence based decision making; and provision of quality $\mathrm{MNCH}$ services. A sustained government and partner's commitment, the Primary Health Care Unit with its home grown innovative Health Extension Program that utilizes the Health Development Army as platform for social mobilization, and strengthened referral and linkage will continue to be the basis for continued gains in newborn and child health. ${ }^{12}$ Even though the impact of the intervention reduced under-five mortalities from 67 per 1000 live births to 55 per 1000 live births in 2019, the figure is still very high and needs adjustment. ${ }^{13}$

Although different studies have been conducted in Ethiopia with regard to factors associated with under-five mortality, there are shortcomings in the use of all of the nationwide representative data for under-five mortality and consideration of relevant theoretical frameworks developed for developing countries to analyze determinants of under-five mortality. ${ }^{7}$ Knowledge of important predictors of under-five mortality by using relevant theoretical framework $^{14}$ and nationwide representative data is an important indicator and guide for decision makers to develop relevant intervention strategies. Therefore, this study aimed at exploring the proximate determinants of under-five mortality in Ethiopia using EDHS 2016 data.

\section{Methods}

\section{Study Design and Dataset}

The dataset used for this study was obtained from 2016 Ethiopian Demographic Health Surveys conducted from January 18, 2016 to June 27, 2016, across the country. The survey was a population-based cross-sectional study and it is available from the MEASURE DHS database at https:// dhsprogram.com/data/available-datasets.cfm. For the surveys, there were two stages. In the first stage, a total of 645 clusters (202 in urban and 443 in rural) were randomly selected proportional to the household size from the sampling strata and in the second stage, 28 households per cluster were selected using systematic random sampling.

During the surveys, a total of 16,650 households were interviewed from 18,008 selected representative households. For individual interview, 16, 583 eligible women were identified from the interviewed households and interviews with 15,683 women aged 15-49 were completed. ${ }^{7}$ In this survey, 10,641 children aged 0-5 from women who had given birth during the five years preceding the survey were also interviewed. Thus, for this study 10,641 underfive children were included.

\section{Study Variables Outcome Variable}

The outcome variable for this study was the death of under-five children. Thus, all children born within the five years preceding the survey were included in the analysis.

\section{Predictor Variables}

The predictor variables for under-five mortality were categorized into three categories based on Mosley and Chen's (1984) theoretical framework as distal factors/socioeconomic characteristics, intermediate factors/mother's characteristics and proximal factors/child's characteristics, as shown in Figure 1. ${ }^{14}$

Distal factors: educational status of mothers (no education, primary, secondary, higher), household wealth (poorest, poorer, middle, richer, richest), sex of head of

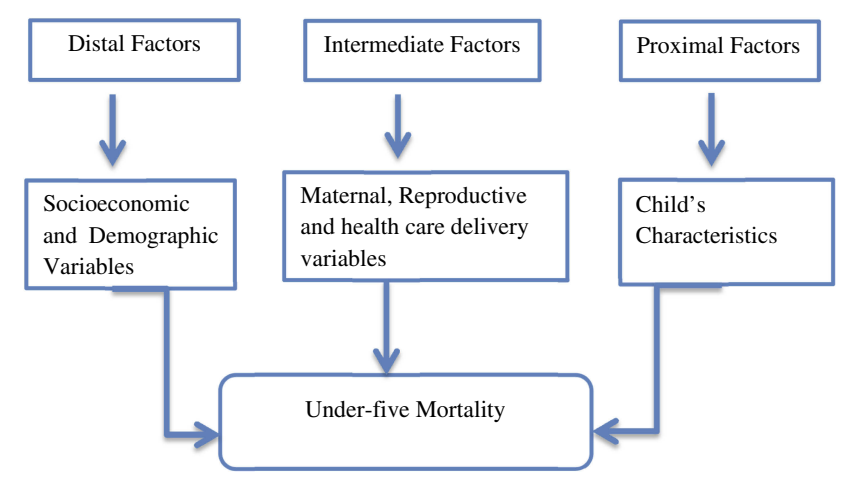

Figure I Conceptual framework for under-five mortality in Ethiopia. 
household (male, female), place of residence (urban, rural) and region (Tigray, Afar, Amhara, Oromia, Somalia, Benishangul, SNNPR, Gambela, Harari, Diredawa, Addis Ababa); intermediate factors: preceding birth interval in months $(<24,24-47,>47)$, mother's age at first birth $(<15,15-25,>25)$, birth order $(<3,3-4,>4)$, place of delivery (home, health institutions), number of antenatal care visits during pregnancy $(<4, \geq 4)$ and proximal factors: plurality (single, multiple), size of child at birth (large, larger than average, average, smaller than average, very small) and sex of child (male, female) were considered as predictor variables of under-five mortality in Ethiopia.

\section{Statistical Analysis}

Bivariate analysis was conducted to assess the association between predictor variables and outcome variable of the study using $\chi^{2}$ tests. Those predictor variables significantly associated with outcome variable were included in the multivariable logistic regression model in which the odds ratio with $95 \%$ confidence intervals was estimated to identify the predictors of under-five mortality in Ethiopia. A p-value less than 0.05 was employed to declare statistical significance.

\section{Results \\ Distal/Socio-Economic Characteristics of the Study Participants}

In this study, approximately two-thirds of children (64.3\%) were born to mothers with no education. Concerning the household wealth index, 7241 (68\%) children were from households with wealth index of middle income and below. In this study, in approximately four-fifths $(78.8 \%)$ of households, the head of the household was male. Similarly, four from five children were from rural residence. With respect to the regional distribution of the study participants, Oromia and Somali bore the lion's share $(14.9 \%$ and $14.1 \%$ respectively), whereas, the lowest $(4.3 \%)$ number of under-five children was recorded in the main capital, Addis Ababa (Table 1).

\section{Intermediate/Mother's Characteristics}

With regard to the birth interval, approximately half (51.6\%) of mothers' gave birth with preceding birth intervals of $24-47$ months. The remaining $2118(25 \%)$ and 1974 (23.3\%) gave birth to child with preceding birth intervals of $<24$ months and $>47$ months, respectively. In this study, close to $90 \%$ (9374) of mothers' age at first birth was 15-25 years. With respect to the order of children born into the family, about 37\% (3967) of mothers gave birth with the birth order of less than three. In this study, home delivery was predominant in which about $68 \%$ (7155) of mothers delivered at home. With regard to ANC follow up, for the great majority of mothers, number of ANC visits was less than four (Table 1).

\section{Proximal/Child's Characteristics}

From a total of 10,461 under-five children, the great majority $97.4 \%(10,363)$ were singletons. With regard to size of child at birth, 9.7\% (1025) were smaller than average size and $17.7 \%$ (1865) were very small sized children at birth. In this study, male to female child sex ratio was approximately 1:1 (Table 1 ).

\section{Prevalence of Under-Five Mortality in Ethiopia}

From a total of 10,641 under-five children included in this study, $635(6 \%)$ died before celebrating their first five years of life. This is approximated to under-five mortality rate of 67 per 1000 live births. Majority of under-five deaths $(4.2 \%$ and $5.3 \%)$ were attributable to uneducated status of mothers and rural residence, respectively (Table 1). Additionally, significantly higher under-five mortality was recorded among home delivery, frequency of ANC visits < four times, and singleton births (Table 1)

\section{Determinants of Under-Five Mortality in Ethiopia}

During bivariate regression analysis, four variables from distal, two variables from intermediate, and three variables from proximal characteristics of the study participants were included into multivariate binary logistic regression analysis. These included: maternal education, household wealth index, place of residence, geographical region, preceding birth interval, place of delivery, plurality, size of child at birth and sex of the child. In the final model, place of residence, preceding birth interval, plurality, size of the child at birth, and sex of child showed significant association with under-five mortality.

The odds of under-five mortality were higher among children with rural residence compared to children with urban residence $(\mathrm{AOR}=2.0,[1.20,3.30], P=0.008)$. Similarly, the odds of under-five mortality were higher among mothers' who gave birth withpreceding birth intervals of less than 24 months $(\mathrm{AOR}=2.12, \mathrm{CI}=[1.72,2.61]$, 
Table I Characteristics and Prevalence for Under-Five Mortality in Ethiopia, 2016 EDHS

\begin{tabular}{|c|c|c|c|c|c|c|}
\hline \multirow[t]{2}{*}{ Characteristics/Variables } & \multirow[t]{2}{*}{ Categories } & \multirow{2}{*}{$\begin{array}{l}\text { Total } \\
N=|0,64|\end{array}$} & \multicolumn{2}{|c|}{ Status of the Child } & \multirow[t]{2}{*}{$x^{2}$} & \multirow[t]{2}{*}{ P-value } \\
\hline & & & Dead & Alive & & \\
\hline $\begin{array}{l}\text { Distal Factors } \\
\text { Mother's Education }\end{array}$ & $\begin{array}{l}\text { No education } \\
\text { Primary } \\
\text { Secondary } \\
\text { Higher }\end{array}$ & $\begin{array}{l}6838(64.3) \\
2678(25.2) \\
734(6.9) \\
391(3.7)\end{array}$ & $\begin{array}{l}45 \mid(4.2) \\
140(1.3) \\
37(0.3) \\
7(0.1)\end{array}$ & $\begin{array}{l}6387(60.0) \\
2538(23.9) \\
697(6.6) \\
384(3.6)\end{array}$ & 20.7 & 0.000 \\
\hline Household Wealth & $\begin{array}{l}\text { Poorest } \\
\text { Poorer } \\
\text { Middle } \\
\text { Richer } \\
\text { Richest }\end{array}$ & $\begin{array}{l}3993(37.5) \\
1782(16.7) \\
1466(13.8) \\
1308(12.3) \\
2092(19.7)\end{array}$ & $\begin{array}{l}287(2.7) \\
112(1.1) \\
80(0.8) \\
81(0.8) \\
75(0.7)\end{array}$ & $\begin{array}{l}3706(34.8) \\
1670(15.7) \\
1386(13.0) \\
1227(11.5) \\
2017(19.0)\end{array}$ & 32.9 & 0.000 \\
\hline Sex of Household Head & $\begin{array}{l}\text { Male } \\
\text { Female }\end{array}$ & $\begin{array}{l}8383(78.8) \\
2258(21.2)\end{array}$ & $\begin{array}{l}508(4.8) \\
127(1.2)\end{array}$ & $\begin{array}{l}7875(74.0) \\
2131(20.0)\end{array}$ & 0.601 & 0.438 \\
\hline Place of Residence & $\begin{array}{l}\text { Urban } \\
\text { Rural }\end{array}$ & $\begin{array}{l}1974(18.6) \\
8667(81.4)\end{array}$ & $\begin{array}{l}67(0.6) \\
568(5.3)\end{array}$ & $\begin{array}{l}1907(17.9) \\
8099(76.1)\end{array}$ & 28.6 & 0.000 \\
\hline Region & $\begin{array}{l}\text { Tigray } \\
\text { Afar } \\
\text { Amhara } \\
\text { Oromia } \\
\text { Somali } \\
\text { Benishangul } \\
\text { SNNPR } \\
\text { Gambela } \\
\text { Harari } \\
\text { Drie Dawa } \\
\text { Addis Ababa }\end{array}$ & $\begin{array}{l}1033(9.7) \\
1062(10.0) \\
977(9.2) \\
1581(14.9) \\
1505(14.1) \\
879(8.3) \\
1277(12.0) \\
714(6.7) \\
605(5.7) \\
547(5.1) \\
461(4.3)\end{array}$ & $\begin{array}{l}41(0.4) \\
90(0.8) \\
49(0.5) \\
87(0.8) \\
103(1.0) \\
64(0.6) \\
71(0.7) \\
44(0.4) \\
41(0.4) \\
31(0.3) \\
14(0.1)\end{array}$ & $\begin{array}{l}992(9.3) \\
972(9.1) \\
928(8.7) \\
1494(14.0) \\
1402(13.2) \\
815(7.7) \\
1206(11.3) \\
670(6.3) \\
564(5.3) \\
516(4.8) \\
447(4.2)\end{array}$ & 34.5 & 0.000 \\
\hline $\begin{array}{l}\text { Intermediate/Mother's Characteristics } \\
\text { Preceding Birth Interval in Months }\end{array}$ & $\begin{array}{l}<24 \\
24-47 \\
>47\end{array}$ & $\begin{array}{l}2118(25.0) \\
4368(51.6) \\
1974(23.3)\end{array}$ & $\begin{array}{l}204(2.4) \\
211(2.5) \\
79(0.9)\end{array}$ & $\begin{array}{l}1914(22.6) \\
4157(49.1) \\
1895(22.4)\end{array}$ & 75.6 & 0.000 \\
\hline Mother's Age at I ${ }^{\text {st }}$ Birth & $\begin{array}{l}<15 \\
15-25 \\
>25\end{array}$ & $\begin{array}{l}622(5.8) \\
9374(88.1) \\
645(6.1)\end{array}$ & $\begin{array}{l}44(0.4) \\
557(5.2) \\
34(0.3)\end{array}$ & $\begin{array}{l}578(5.4) \\
8817(82.9) \\
611(5.7)\end{array}$ & 1.9 & 0.382 \\
\hline Birth Order & $\begin{array}{l}<3 \\
3-4 \\
>4\end{array}$ & $\begin{array}{l}3968(37.3) \\
2860(26.9) \\
3813(35.8)\end{array}$ & $\begin{array}{l}23 \mid(2.2) \\
153(\mid .4) \\
25 \mid(2.4)\end{array}$ & $\begin{array}{l}3737(35.1) \\
2707(25.4) \\
3562(33.5)\end{array}$ & 4.7 & 0.097 \\
\hline Place of Delivery & $\begin{array}{l}\text { Home } \\
\text { Health institution }\end{array}$ & $\begin{array}{l}7155(68.0) \\
3361(32.0)\end{array}$ & $\begin{array}{l}484(4.6) \\
145(I .4)\end{array}$ & $\begin{array}{l}667 I(63.4) \\
3216(30.6)\end{array}$ & 24.4 & 0.000 \\
\hline
\end{tabular}

(Continued) 
Table I (Continued).

\begin{tabular}{|c|c|c|c|c|c|c|}
\hline \multirow[t]{2}{*}{ Characteristics/Variables } & \multirow[t]{2}{*}{ Categories } & \multirow{2}{*}{$\begin{array}{l}\text { Total } \\
N=|0,64|\end{array}$} & \multicolumn{2}{|c|}{ Status of the Child } & \multirow[t]{2}{*}{$x^{2}$} & \multirow[t]{2}{*}{ P-value } \\
\hline & & & Dead & Alive & & \\
\hline ANC Visits During Pregnancy & $\begin{array}{l}<4 \\
\geq 4\end{array}$ & $\begin{array}{l}9929(93.3) \\
712(6.7)\end{array}$ & $\begin{array}{l}594(5.6) \\
4 I(0.4)\end{array}$ & $\begin{array}{l}9335(87.7) \\
67 I(6.3)\end{array}$ & 0.06 & 0.807 \\
\hline $\begin{array}{l}\text { Proximal/Child's Characterist } \\
\text { Plurality }\end{array}$ & $\begin{array}{l}\text { Single birth } \\
\text { Multiple births }\end{array}$ & $\begin{array}{l}10,363(97.4) \\
278(2.6)\end{array}$ & $\begin{array}{l}577(5.4) \\
58(0.5)\end{array}$ & $\begin{array}{l}9786(92.0) \\
220(2.1)\end{array}$ & 112.9 & 0.000 \\
\hline Size of Child at Birth & $\begin{array}{l}\text { Very large } \\
\text { Larger than average } \\
\text { Average } \\
\text { Smaller than average } \\
\text { Very small }\end{array}$ & $\begin{array}{l}1710(16.3) \\
1504(14.3) \\
4419(42.0) \\
1025(9.7) \\
1865(17.7)\end{array}$ & $\begin{array}{l}119(1.1) \\
74(0.7) \\
223(2.1) \\
59(0.6) \\
143(1.4)\end{array}$ & $\begin{array}{l}1591(15.1) \\
1430(13.6) \\
4196(39.9) \\
966(9.2) \\
1722(16.4)\end{array}$ & 22.5 & 0.000 \\
\hline Sex of Child & $\begin{array}{l}\text { Male } \\
\text { Female }\end{array}$ & $\begin{array}{l}5483(51.5) \\
5158(48.5)\end{array}$ & $\begin{array}{l}376(3.5) \\
259(2.4)\end{array}$ & $\begin{array}{l}5107(48.0) \\
4899(46.0)\end{array}$ & 16.0 & 0.000 \\
\hline
\end{tabular}

Note: Data are presented as number (percentages).

Abbreviations: SNNPR, Southern Nation Nationalities and Peoples' Region; ANC, antenatal care.

$P<0.000)$. The odds of under-five mortality were higher for multiple births $(\mathrm{AOR}=4.74, \mathrm{CI}=[3.34,6.69], P<0.000)$ compared to singletons. In a similar fashion, the odds of under-five mortality were higher for very small size children at birth $(\mathrm{AOR}=1.43, \mathrm{CI}=[1.10,1.85], P=0.007)$. The odds of under-five death were also higher for male children $(\mathrm{AOR}=1.30, \mathrm{CI}=[1.07,1.57], P<0.008)$ compared to females (Table 2). The rest of the variables including maternal education, region and place of delivery did not show any significant association with under-five mortality (Table 2).

\section{Discussion}

Currently, reducing under-five mortality and promotion of child health care in low income and resource limited settings is emphasized. ${ }^{8}$ With the end of the MDG era, the international community agreed on a new framework - the Sustainable Development Goals (SDGs) where the target is to end preventable deaths of newborns and children under five years of age. The goal is for all countries to aim to reduce under-five mortality to at least as low as 25 per 1000 live births. ${ }^{2}$ In this study, we assessed prevalence and determinants of under-five mortality in Ethiopia, using EDHS 2016 data.

The prevalence rate of under-five mortality in this study was approximately 67 per 1000 live births. When compared to other similar studies, this finding is higher by eight under-five deaths per 1000 live births $^{8}$ and lower by approximately 17 mortalities per 1000 live births. ${ }^{2,9,15}$ The explanation for this difference might be due to difference in sample size, study setting and definitions. In this study our sample size was relatively large compared to others and socioeconomic status of the participants in Ethiopia was relatively low.

The most significant predictors identified were, place of residence, preceding birth interval, plurality, size of child at birth and sex of the child. This study found that the odds of under-five mortality were significantly higher for children living in rural setting. This study was consistent with the finding from Nigeria ${ }^{9}$ and inconsistent with other findings. ${ }^{10,11,16}$ The differences can be explained by difference in study design and sample size. In our study we used only one country's data, but the previous studies used larger sample size by including five African countries' survey data in their study.

Similarly, in this study the odds of under-five mortality were significantly higher among children born from mothers with preceding birth interval of less than 24 months. Compared to other similar studies, this finding was consistent with findings from Ethiopia. ${ }^{17-19}$ With regard to plurality, children born as multiple births had higher risk of under-five mortality as compared to singletons. This finding is 
Table 2 Multivariate Binary Logistic Regression Analysis for Under-Five Mortality in Ethiopia, 2016 EDHS

\begin{tabular}{|c|c|c|c|c|}
\hline Characteristics/Variables & Categories & $\beta^{\text {s }}$ & ORs $(95 \% \mathrm{Cl})$ & P-value \\
\hline \multicolumn{5}{|c|}{ A. Distal/Socioeconomic Factors } \\
\hline \multicolumn{5}{|l|}{ Mother's Education } \\
\hline & No education & & I & \\
\hline & Primary & -0.05 & $0.95[0.74,1.23]$ & 0.696 \\
\hline & Secondary & 0.06 & $1.06[0.61,1.84]$ & 0.836 \\
\hline & Higher & -0.25 & $0.78[0.30,2.10]$ & 0.611 \\
\hline \multicolumn{5}{|l|}{ Household Wealth } \\
\hline & Poorest & -0.02 & $0.99[0.72,1.34]$ & 0.926 \\
\hline & Poorer & -0.04 & $0.96[0.69,1.35]$ & 0.824 \\
\hline & Middle & & & \\
\hline & Richer & 0.06 & $1.06[0.73,1.53]$ & 0.760 \\
\hline & Richest & 0.08 & $1.08[0.66,1.77]$ & 0.765 \\
\hline \multicolumn{5}{|l|}{ Place of Residence } \\
\hline & Urban & & 1 & \\
\hline & Rural & 0.67 & $2.00[1.20,3.30]$ & 0.008 \\
\hline \multicolumn{5}{|l|}{ Region } \\
\hline & Tigray & -0.03 & $0.97[0.36,2.61]$ & 0.958 \\
\hline & Afar & 0.20 & $1.22[0.46,3.23]$ & 0.697 \\
\hline & Amhara & -0.04 & $0.96[0.36,2.30]$ & 0.935 \\
\hline & Oromia & -0.06 & $0.94[0.36,2.50]$ & 0.907 \\
\hline & Somali & -0.02 & $0.98[0.38,2.66]$ & 0.970 \\
\hline & Benishangul & 0.34 & $\mathrm{I} .4 \mathrm{I}[0.53,3.78]$ & 0.491 \\
\hline & SNNPR & -0.01 & $0.99[0.38,2.64]$ & 0.986 \\
\hline & Gambela & 0.25 & $1.28[0.48,3.43]$ & 0.618 \\
\hline & Harari & 0.19 & $1.21[0.45,3.28]$ & 0.703 \\
\hline & Drie Dawa & 0.09 & $1.09[0.40,3.02]$ & 0.869 \\
\hline & Addis Ababa & & 1 & \\
\hline \multirow{2}{*}{\multicolumn{5}{|c|}{$\begin{array}{l}\text { B. Intermediate/Mother's Characteristics } \\
\text { Preceding Birth Interval in Months }\end{array}$}} \\
\hline & & & & \\
\hline & $<24$ & 0.75 & $2.12[1.72,2.61]$ & 0.000 \\
\hline & $24-47$ & & & \\
\hline & $>47$ & -0.14 & $0.87[0.65,1.15]$ & 0.314 \\
\hline \multicolumn{5}{|l|}{ Place of Delivery } \\
\hline & Home & 0.22 & $1.24[0.95,1.63]$ & 0.121 \\
\hline & Health institution & & 1 & \\
\hline \multicolumn{5}{|c|}{ C. Proximal/Child's Characteristics } \\
\hline \multicolumn{5}{|l|}{ Plurality } \\
\hline & Single birth & & 1 & \\
\hline & Multiple births & 1.56 & $4.74[3.34,6.69]$ & 0.000 \\
\hline \multicolumn{5}{|l|}{ Size of Child at Birth } \\
\hline & Very large & 0.34 & $1.43[1.09,1.7]$ & 0.010 \\
\hline & Larger than average & -0.05 & $0.95[0.69,1.30]$ & 0.754 \\
\hline & Average ${ }^{(\text {ref })}$ & & 1 & \\
\hline & Smaller than average & 0.08 & $1.08[0.77,1.51]$ & 0.661 \\
\hline & Very small & 0.35 & $1.43[1.10,1.85]$ & 0.007 \\
\hline \multicolumn{5}{|l|}{ Sex of Child } \\
\hline & Male & 0.26 & $1.30[1.07,1.57]$ & 0.008 \\
\hline & Female & 1 & & \\
\hline
\end{tabular}

Abbreviations: $\beta^{\text {ss }}$, the amount of effect of the independent variables; OR, odds ratios; $\mathrm{Cl}$, confidence interval. 
consistent with other findings using 2011 EDHS data. ${ }^{19,20} \mathrm{In}$ relation to size of child at birth, the odds of under-five mortality were higher for very small sized child at birth compared to average sized child at birth. Compared to findings from other settings, this study's findings are consistent with those of a study conducted in India ${ }^{10,21}$ in which the risk of death was higher for small-sized than average-sized babies at birth. With regard to the sex of the child, the odds of underfive mortality were higher for male children compared to female children, in this study. This finding is consistent with studies from other settings. ${ }^{10,17,19}$

Unlike other studies done so far, ${ }^{9,19,21,22}$ maternal education, household wealth index, region and place of delivery were not independently associated with under-five mortality in this study.

\section{Strengths and Weaknesses of the Study}

Our study is strong and representative since it used the nationwide survey data with large sample size. Additionally, use of appropriate theoretical framework relevant to developing countries to assess under-five mortality also makes this study strong. Although, this study is not free from limitation since some important variables, as per different literatures, believed to predict under-five mortality are missing. Additionally, the cross-sectional nature of the study design might have introduced recall bias into this study.

\section{Conclusion}

The prevalence of under-five mortality is still highest in Ethiopia and it was significantly associated with place of residence, preceding birth interval, plurality, size of child at birth and sex of the child. Thus, special emphasis should be placed on children with rural residence, preceding birth interval of less than 24 months, very small size of the child at birth and male children.

\section{Abbreviations}

CI, confidence interval; EDHS, Ethiopian Demographic Health Survey; AOR, adjusted hazard ratio; MEASURE DHS, monitoring and evaluation to assess and use results demographic and health surveys; SNNPR, Southern Nations, Nationalities, and Peoples' Region.

\section{Paper Context}

Under-five mortality is a global concern in general and in particular in developing nations. It is highest in Ethiopia and the determinant factors have not been exhaustively researched using relevant theoretical frameworks. Better understanding of the determinant factors of under-five mortality is important to develop relevant interventions. We analyzed data of 10,641 under-five children and found that under-five mortality was significantly associated with place of residence, birth interval, plurality, size of child at birth, and sex of the child.

\section{Ethical Approval and Consent to Participate}

Ethical clearance for the 2016 EDHS was provided by the Ethiopian Health and Nutrition Research Institute (EHNRI) Review Board, the National Research Ethics Review Committee (NRERC) at the Ministry of Science and Technology, the Institutional Review Board of ICF International, and the communicable disease control (CDC). Additionally, written consent for participation was obtained from each respondent. However, the dataset of the 2016 EDHS is not available as a public domain survey dataset. The authors requested access to the data from demographic, health survey program team and access was granted to use the data for this research.

\section{Availability of Data and Material}

The datasets used and/or analyzed during the current study are available from the Ethiopian statistical agency and ministry of health.

\section{Acknowledgment}

The authors would like to acknowledge that the Ethiopian Demographic and Health Survey 2016 data used in this study were obtained from the DHS office, they have given permission to access the data, after we have prepared the proposal on the title.

\section{Author Contributions}

All authors contributed to data analysis, drafting and revising the article, gave final approval of the version to be published, and agree to be accountable for all aspects of the work.

\section{Disclosure}

The authors report no conflicts of interest in this work.

\section{References}

1. UNICEF. Levels and Trends in child mortality. Accessed and cited on September 15, 2019. Available from: https://www.unicef.org/media/ 60561/file/UN-IGME-child-mortality-report-2019.pdf. 
2. WHO. Global Health Observatory (GHO) data 2017; 2017. Available from: https://www.who.int/gho/child_health/mortality/mortality_ under_five_text/en/.Accessed December 3, 2019.

3. United Nations General Assembly, Transforming our world: the 2030 Agenda for Sustainable Development, New York, NY, USA: UnitedNations; 2015. Available from: https://sustainabledevelopment. un.org/post2015/transformingourworld. Accessed October 21, 2019

4. Kalipeni E, Iwelunmor J, Grigsby-Toussaint D. Maternal and child health in Africa for sustainable development goals beyond 2015. Global Public Health. 2017;12(6):643-647. doi:10.1080/17441692.2017.1304622

5. UNICEF, WHO, and World Bank and UN Population Division, Levels \& Trends in Child Mortality: report 2015, Estimates Developed by the UN Inter-Agency Group for Child Mortality Estimation, New York, NY, USA: United Nations Children's Fund; 2015. Available from: https://childmortality.org/flesv20/download/ IGMEreport2015. Accessed December 3, 2019

6. UNICEF. The State of the World's Children 2016: A Fair Chance for Every Child. 2016.

7. Central Statistical Agency (CSA) [Ethiopia] and ICF. Ethiopia Demographic and Health Survey 2016. Addis Ababa, Ethiopia, and Rockville, Maryland, USA: CSA and ICF; 2016.

8. Dendup T, Zhao Y, Dema D. Factors associated with under-five mortality in Bhutan: an analysis of the Bhutan National Health Survey 2012. BMC Public Health. 2018;18:1375. doi:10.1186/s12889-018-6308-6

9. Yaya S, Ekholuenetale M, Tudeme G, Vaibhav S, Bishwajit G, Kadio B. Prevalence and determinants of childhood mortality in Nigeria. $B M C$ Public Health. 2017;17:485. doi:10.1186/s12889-017-4420-7

10. Yaya S, Bishwajit G, Okonofua F, Uthman OA. Underfive mortality patterns and associated maternal risk factors in sub-Saharan Africa: amulti-country analysis. PLoSONE. 2018;13(10):e0205977. doi:10. 1371/journal.pone.0205977

11. Tlou B, Sartorius B, Tanser F. Space-time variations in child mortality in a rural South African population with high HIV prevalence $(2000 \pm 2014)$. PLOSONE. 2017;12(8):e0182478. doi:10.1371/journal.pone.0182478

12. FMOH (Ethiopia). National strategy for new born and child survival in Ethiopia2015/16-2019/20; maternal and child health directorate federal ministry of health. June 2015, Addis Ababa, Ethiopia. Available from: https://www.healthynewbornnetwork.org/hnncontent/uploads/nationalstrategy-for-newborn-and-child-survival-inethiopia-201516-201920.pdf. Accessed December 3, 2019.
13. Ethiopian Public Health Institute (EPHI) [Ethiopia] and ICF. Ethiopia Mini Demographic and Health Survey 2019: key Indicators. Rockville, Maryland, USA: EPHI and ICF; 2019. Available from: https://www.unicef.org/ethiopia/reports/2019-ethiopia-minidemographic-and-health-survey.Accessed December 3, 2019.

14. Mosley WH, Chen LC. An analytical framework for the study of child survival in developing countries. Popul Dev Rev. 1984;10: 25-45. doi:10.2307/2807954

15. World Bank. Estimates developed by the UN inter-agency group for child mortality estimation (UNICEF, WHO, World Bank, UN DESA population division) 2017; 2017. Accessed August 2019.

16. Abu IN, Madu IA, Ajaero CK. The prevalence and determinants of under-five mortality in Benue State, Nigeria. SAGE Open. 2015;1-11. doi: $10.1177 / 2158244015611938$

17. Getachew Y, Bekele S. Survival analysis of under-five mortality of children and its associated risk factors in Ethiopia. $J$ Biosens Bioelectron. 2016;7:3. doi:10.4172/2155-6210.1000213

18. Woldeamanuel BT. Socioeconomic, demographic, and environmental determinants of under-5 mortality in Ethiopia: evidence from Ethiopian demographic and health survey, 2016. Child Dev Res. 2019;2019, 15. Article ID 1073782. doi:10.1155/2019/1073782

19. Gebretsadik S, Gabreyohannes E. Determinants of under-five mortality in high mortality regions of Ethiopia: an analysis of the 2011 Ethiopia demographic and health survey data. Int J Popul Res. 2016;2016:7. Article ID 1602761. doi:10.1155/2016/1602761

20. Dwomoh D, Amuasi S, Agyabeng K, et al. Understanding the determinants of infant and under-five mortality rates: a multivariate decomposition analysis of Demographic and Health Surveys in Ghana, 2003, 2008 and 2014. BMJ Global Health. 2019;4:e01658. doi:10.1136/bmjgh-2019-001658

21. Mani K, Sada WN, Ravindra PM. Determinants of Under-five mortality in rural empowered action group states in India: an application of cox frailty model. Int MCH AIDS. 2012;1(1):60-72. doi:10.21106/ ijma. 9

22. Aheto JMK. Predictive model and determinants of under-five child mortality: evidence from the 2014 Ghana demographic and health survey. BMC Public Health. 2019;19:64. doi:10.1186/s12889-019$6390-4$
Pediatric Health, Medicine and Therapeutics

\section{Publish your work in this journal}

Pediatric Health, Medicine and Therapeutics is an international, peerreviewed, open access journal publishing original research, reports, editorials, reviews and commentaries. All aspects of health maintenance, preventative measures and disease treatment interventions are addressed within the journal. Practitioners from all disciplines are invited to submit their work as well as healthcare researchers and patient support groups. The manuscript management system is completely online and includes a very quick and fair peer-review system. Visit http://www.dovepress.com/testimonials.php to read real quotes from published authors. 